\title{
APPLICATION OF WATER SPRAYS TO INDUSTRIAL OIL COOKER FIRE
}

\author{
SOONIL NAM
}

FM Global Research, 1151 Boston-Providence Turnpike, Norwood, Massachusetts 02062, U. S. A.

\begin{abstract}
Fourteen full-scale fire tests were conducted to determine the optimal design parameters of water-based protection systems against large industrial oil cooker fires. All but one test fires were self-ignited by heating the oil inside a test pan above its auto-ignition temperature. Three test mock-ups that simulated industrial oil cookers were fabricated for the tests: $3.0 \mathrm{~m}$ long by $2.4 \mathrm{~m}$ wide, $6.1 \mathrm{~m}$ long by $2.4 \mathrm{~m}$ wide, and $12.2 \mathrm{~m}$ long by 2.4 $\mathrm{m}$ wide. Three types of water spray systems utilizing $13 \mathrm{~mm}$ orifice sprinklers, $13 \mathrm{~mm}$ orifice spray nozzles, and $6.4 \mathrm{~mm}$ orifice spray nozzles, respectively, were installed to discharge water with various discharge densities into burning oil inside a pan. Rapid fire suppression was achieved, although fire flare-up was very pronounced and the interaction between the fire and the water spray was very intense. Test results showed that the systems using the nominal $6.4 \mathrm{~mm}$ orifice spray nozzles placed in a double-row $0.76 \mathrm{~m}$ above the oil surface, discharging a $20 \mathrm{~mm} / \mathrm{min}$ density, yielded the best performance. The tests also indicated that bronze sprinklers or bronze spray nozzles may not be strong enough to use against auto-ignition fires inside a cooker. None of the stainless steel sprinklers or spray nozzles showed any damage after they were exposed to several test fires.
\end{abstract}

KEY WORDS: industrial oil cooker, AIT fire, water spray

\section{INTRODUCTION}

Industrial oil cookers are used to fry foods such as potato chips, donuts, nuts, fish sticks, meat and poultry products. They generally have large cooking surfaces, in the range of tens of square meters. The cookers contain from a few hundred to several thousand liters of cooking oils, which are usually vegetable oils. The industrial cookers typically consist of pans, moveable hoods, and product conveyor systems. The product conveyor belts typically run through the inside of the cooker pan, immersed in oil, during the normal operation period[1].

Some cookers are heated indirectly by exchanging heat with a heat transfer fluid or steam. Other cookers are heated directly by gas/oil fired radiant tubes beneath the pan or flame impingement on the bottom of the pan[1]. Although there is a degree of difference in fire risk depending on which heating system is employed, all cookers present the hazards associated with large amount of heated combustible liquids in open tanks[1]. Recent loss events indicated that the oil cookers were mainly responsible for the large fire losses in the facilities. The oil cookers were either the origin of the fire or were the main fuel source, even in cases when the fire originated elsewhere. These loss events also indicated that the protection based on discharge of $\mathrm{CO}_{2}$, which has been the main protection scheme 
in the industry, was not effective mainly because of the lack of cooling capability of $\mathrm{CO}_{2}$ against the burning oil. The use of water based systems, therefore, seemed to be a more reliable method of protecting against large industrial oil cooker fires.

Since there was no previous direct test data pertaining to the relation between industrial oil cooker fires and water sprays from sprinklers or spray nozzles, full-scale fire tests were sought to determine the optimal design parameters for water-based protection systems. Cooker mock-ups were built for the tests. The mock-ups had the maximum length of $12.2 \mathrm{~m}$ with an $2.4 \mathrm{~m}$ width. A general consensus was that the size of the mockup would cover more than $60 \%$ of the existing industrial oil cookers in the world.

The tests were conducted with a 127-mm depth of Canola oil in the pan. The cooker mock-ups were tested in two positions, namely a hood-up and a hood-down position. The clearance between the bottom of the hood and the rim of the pan would be $0.46 \mathrm{~m}$ at the hood-up position and $0.05 \mathrm{~m}$ at the hood-down position.

\section{FIRE TEST PREPARATION}

\subsection{Characteristics of Canola oil}

A few laboratory and medium scale tests were conducted to determine some properties of the oil. In order to obtain the heat release rate (HRR), a pool fire over a $1.2 \mathrm{~m}$ diameter pan was used. The pan was placed under a fire-products collector and was filled with 45 liters of Canola oil, which provided a 38-mm oil depth. A six-nozzle-heptane burner under the pan supplied heat until the oil self-ignited.

The measured properties were as follows: (1) Density at Room Temperature: $0.93 \mathrm{~kg} /$, (2) Specific Heat Averaged Between $293 \mathrm{~K}$ and $433 \mathrm{~K}: 2.5 \mathrm{~kJ} / \mathrm{kg} \mathrm{K}$, (3) Flash point: $503 \mathrm{~K}$, (4) Auto Ignition Temperature (AIT): 603K, and (5) Heat Release Rate per Unit Surface Area: $1.81 \mathrm{MW} / \mathrm{m}^{2}$.

\subsection{Cooker Mock-ups}

Three cooker mock-ups, A, B, and C, were fabricated. Each cooker mock-up consisted of a pan and a hood. The pan for Mock-up A was $3.0 \mathrm{~m}$ long and $2.4 \mathrm{~m}$ wide. The depth of the pan was $343 \mathrm{~mm}$, which would provide a $216 \mathrm{~mm}$ free board once the pan was filled with a $127 \mathrm{~mm}$ deep cooking oil, as required for the tests. The pan was fabricated with nominal 11-mm thick steel. The dimension of the hood for Mock-up A was $3.2 \mathrm{~m}$ long, $2.6 \mathrm{~m}$ wide, and $0.76 \mathrm{~m}$ deep. Both ends of the hood were open. There was a $0.51-\mathrm{m}$ diameter hole on top of the hood at the center. The holes simulated the connection with the exhaust duct. The distance from the center of the hole to either end of the hood was $1.5 \mathrm{~m}$.

The pan for Mock-up B was $6.1 \mathrm{~m}$ long and $2.4 \mathrm{~m}$ wide. The dimension of the hood for Mock-up B was $6.2 \mathrm{~m}$ long, $2.6 \mathrm{~m}$ wide, and $0.76 \mathrm{~m}$ deep. Both ends of the hood were open. There were two $0.51 \mathrm{~m}$ diameter holes on top of the hood. The holes simulated the connections with two exhaust ducts. The distance from the center of each hole to its nearest end of the hood was $1.5 \mathrm{~m}$. The pan for Mock-up C was $12.2 \mathrm{~m}$ long and $2.4 \mathrm{~m}$ wide. The depth of the pan was $343 \mathrm{~mm}$. The dimension of the hood of Mock-up C was 
$12.3 \mathrm{~m}$ long, $2.6 \mathrm{~m}$ wide, and $0.76 \mathrm{~m}$ deep. Both ends of the hood were open. There were two $0.51-\mathrm{m}$ diameter holes on top of the hood. The distance from the center of each hole to the nearest end of the hood was $1.5 \mathrm{~m}$. In the test program, Mock-up C was assembled by combining Mock-up B with two Mock-up As.

\subsection{Test Site}

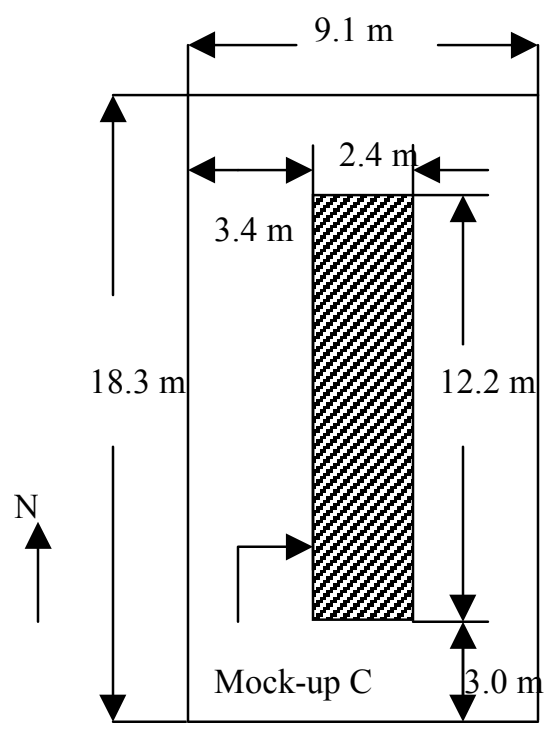

Fig. 1 Plan view of the test facility with Mock-up C inside.

The fire tests were conducted at a facility of the Fire and Safety Detachment of the US Coast Guard located at Little Sand Island, Mobile, Alabama, USA. The lower part of the facility was built of steel. The floor of the structure was a steel deck. It was $18.3 \mathrm{~m}$ long (in south-north direction) and $9.1 \mathrm{~m}$ wide as shown in Fig. 1.

The heights of the walls were $3.7 \mathrm{~m}$ along the longitudinal direction and $4.0 \mathrm{~m}$ along the transverse direction. No ceiling was provided in order to avoid a potential flashover of the facility, as the test fires were expected to generate very high heat release rates. There was a $1-\mathrm{m}$ clearance between the bottom of the cooker mockups and the floor of the test facility so that a heating system could be placed under the pans.

\subsection{Heating System}

In order to heat the oil inside the pans, a heating system using propane gas was fabricated. It was estimated that every liter of the oil inside a test pan would require $0.72 \mathrm{MJ}$ to have the oil reach its auto-ignition temperature (AIT), assuming that: i) the heat capacity of the oil remains constant as $2.5 \mathrm{~kJ} / \mathrm{kg} \mathrm{K}$ between room temperature and the AIT, and ii) the initial oil temperature is $293 \mathrm{~K}$. The largest scale test among the test series would be the one involving Mock-up C with a 127-mm depth of oil; the amount of oil would be approximately 3800 liters. In order to have the oil reach its AIT within 1 hour from ignition, the heating system would need to provide a heat release rate of $1.52 \mathrm{MW}$, assuming that the heating efficiency of the system would be $50 \%$.

The heating system was designed to cover the whole surface area, $29.3 \mathrm{~m}^{2}$, underneath the pan of Mock-up C. Propane gas was supplied through twelve pipelines. At each pipeline, which was installed across the bottom of the pan along the transverse direction, there were 4 ports. At each port, $0.3-\mathrm{m}$ long $50-\mathrm{mm}$ diameter pipe was vertically welded so that the open end of the $50-\mathrm{mm}$ diameter pipe could function as a gas nozzle. When all the nozzles were lit, this arrangement provided 48 heat sources that distributed heat relatively 
uniformly throughout the pan surface. The propane tank pressure was initially maintained as 5 bar $(0.5 \mathrm{MPa})$ but slowly decreased as tests progressed.

\subsection{Instrumentation}

\subsubsection{Temperature Measurements}

Oil temperatures inside the pan and air temperatures above the oil surface were measured. In Tests 5 and 6, three thermocouple trees were placed in the pan. Three thermocouples (Type K, 18 gauge) were attached to each tree, $12 \mathrm{~mm}, 38 \mathrm{~mm}$, and $300 \mathrm{~mm}$ above the bottom of the pan, respectively. In Tests 7 through 10, four thermocouple trees were placed in the pan. At each tree, eight thermocouples were attached. The elevation of each thermocouple was $25 \mathrm{~mm}, 51 \mathrm{~mm}, 76 \mathrm{~mm}, 102 \mathrm{~mm}, 127 \mathrm{~mm}, 152 \mathrm{~mm}, 254 \mathrm{~mm}$, and $381 \mathrm{~mm}$ above the bottom of the pan. In Tests 11 through 14, two thermocouple trees, identical to those used in Tests 7 through 10, were placed in the pan.

\subsubsection{Video Monitoring}

At least four video cameras were used in every test. Three cameras were placed outside the walls through three small holes. The last camera was placed inside the test facility. In Tests 8 through 14, one more camera was used to take aerial views of the tests in order to capture more complete test views. The aerial-view camera was elevated between 6 and 9 $\mathrm{m}$ from the ground surface outside the test room.

\section{DESCRIPTION OF FIRE TESTS}

Fourteen full-scale fire tests were conducted[2]. Due to the space limitation, only eight tests will be described here. The test numbers of those are 5, 6, 7, 9, 10, 11, 13, and 14 .

\subsection{Test 5}

Test 5 was conducted with Mock-up B (see Fig. 2). The $6.1 \mathrm{~m}$ long by $2.4 \mathrm{~m}$ wide pan was installed with the "hood-up" position. Four water spray nozzles (13 $\mathrm{mm}$ orifice, $\mathrm{K}=103.7 \mathrm{LPM} /[\mathrm{bar}]^{1 / 2}$ ) were installed along the longitudinal axis of the pan $0.76 \mathrm{~m}$ above the surface of the oil. The two most remote nozzles from the center along the longitudinal direction were placed $0.76 \mathrm{~m}$ inward from each end of the pan. The rest of the nozzles were placed $1.52 \mathrm{~m}$ apart from the adjacent ones. The water flow rate of each nozzle was $1.83 \mathrm{l} / \mathrm{s}$, which provided a $30 \mathrm{~mm} / \mathrm{min}$ discharge density. The amount of the oil used in the test was approximately 1900 liters. The test conditions closely reflected those of a real 6.1-m long industrial cooker in a hood-up position.

The ambient temperature was $276 \mathrm{~K}$ and it was windy. It took an exceptionally long time to raise the oil temperature close to its auto-ignition temperature. The operating pressure of the propane gas tank at $16 \mathrm{~min}$ in the heating was reduced to $69 \mathrm{kPa}$ from its initial pressure of $500 \mathrm{kPa}$. (After the test, the number of the propane tanks connected to the pipelines was doubled for future tests.) It took more than 2.5 hours for the heating system to raise the oil temperature to $573 \mathrm{~K}$. An oil soaked mat was ignited and thrown inside the pan underneath the hood in order to ignite the oil. The oil did not catch fire immediately. 
Eventually, flames covering the entire oil surface were established a few minutes later. Twenty seconds later, water was discharged. It took $32 \mathrm{~s}$ to extinguish the pan fire. Heating was provided continuously until $30 \mathrm{~s}$ after extinction of the pan fire.

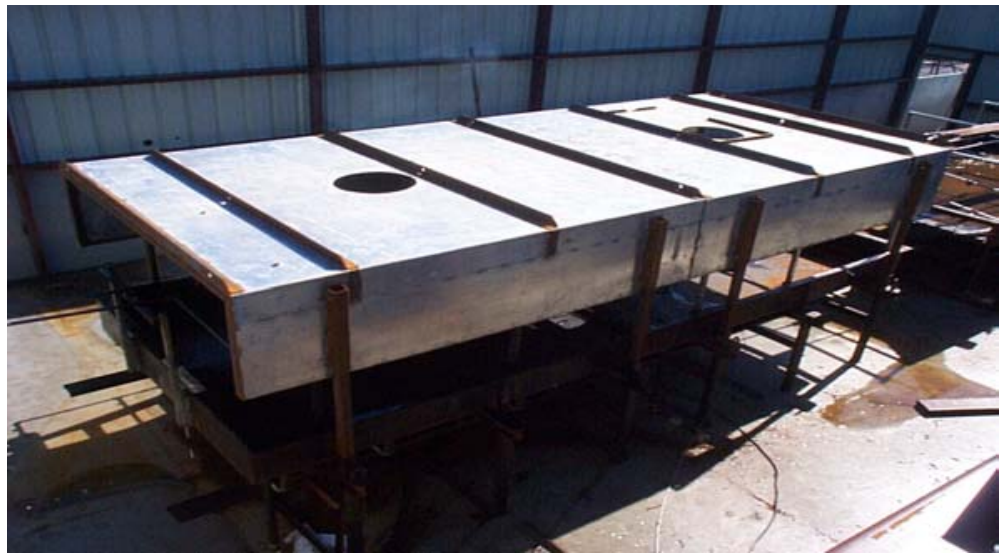

Fig. 2 Photo of Mock-up B setup inside the test facility in Test 5.

\subsection{Test 6}

Test 6 used the same setup as Test 5 except for the number of the spray nozzles, nozzle locations, and the water flow rate. Two water spray nozzles ( $13 \mathrm{~mm}$ orifice, $\mathrm{K}=103.7$ $\mathrm{LPM} /[\mathrm{bar}]^{1 / 2}$ ) were installed along the pan's longitudinal axis $0.76 \mathrm{~m}$ above the oil surface. Each nozzle was placed $1.5 \mathrm{~m}$ inward from each longitudinal end of the pan. The water flow rate of each nozzle was $1.07 \mathrm{l} / \mathrm{s}$, which provided a $8.5 \mathrm{~mm} / \mathrm{min}$ discharge density. The amount of the oil in the pan was approximately 1900 liters.

The ambient temperature was $276 \mathrm{~K}$ and it was windy. The first flames from auto-ignition appeared $1 \mathrm{hr} 10 \mathrm{~min}$ after initiation of the heating system. Flames covering the entire oil surface were well established at $1 \mathrm{hr} 10 \mathrm{~min} 12 \mathrm{~s}$ and the heating system was turned off. Water was discharged at $1 \mathrm{hr} 11 \mathrm{~min} 5 \mathrm{~s}, 53 \mathrm{~s}$ after the free burn started. It took $145 \mathrm{~s}$ to extinguish the fire from the entire surface.

Fire flare-up was very extensive. The surrounding walls were scorched due to the fire flare-up. A post-test observation revealed that the frames of both water spray nozzles were melted down. The videotapes taken during the test confirmed that the frames fell down into the pan during the free-burn stage before the water discharge. It is believed that the water jets coming out of the pipe, where the nozzles no longer existed, vigorously stirred the burning oil inside the pan and this in turn provided vigorous fire flare-up. Huge fireballs were created at the moment of water discharge. A 6-m long fire jet was extracted through the opening between the pan and the hood at the south end of the mockup as if the opening were a nozzle of a rocket propulsion engine. The test strongly suggests that bronze sprinklers or bronze nozzles should not be installed inside a cooker for the protection against AIT fires. 
The pan fire extinction time and the oil cooling time in the test were, respectively, $145 \mathrm{~s}$ and $195 \mathrm{~s}$. The oil cooling time was defined as the time from the starting of water discharge to the time when all the measured oil temperatures inside the pan became lower than $473 \mathrm{~K}$, which was well below the flash point of the oil. It is worth noting that at the fire extinction, the average oil temperatures measured at $89 \mathrm{~mm}$ and $115 \mathrm{~mm}$ below the oil surface were both $484 \mathrm{~K}$. It was likely that the oil temperature at the surface was even lower than $484 \mathrm{~K}$. It thus indicated that the AIT fire was sustained well below the oil's known flash point, which was $503 \mathrm{~K}$. This was believed to be caused by long exposure of the oil to fire and that it had changed the chemical characteristics of the oil. An early test[3] using soy bean oil showed that a previously heated soy bean oil sample self-ignited at $525 \mathrm{~K}$ while a fresh oil sample self-ignited at $619 \mathrm{~K}$. A similar trend with another vegetable oil also had been reported[4] recently ( $573 \mathrm{~K}$ vs. $638 \mathrm{~K})$. This emphasizes the importance of fast extinction of fires and continuous cooling of the oil.

\subsection{Test 7}

Mock-up C, the pan of which was $12.2 \mathrm{~m}$ long by $2.4 \mathrm{~m}$ wide, was installed inside the test facility with the hood-up position. Eight stainless steel water spray nozzles $(13 \mathrm{~mm}$ orifice, $\mathrm{K}=103.7 \mathrm{LPM} /[\mathrm{bar}]^{1 / 2}$ ) were installed along the pan's longitudinal axis $0.76 \mathrm{~m}$ above the oil surface. The two most remote nozzles from the center along the longitudinal direction were placed $0.76 \mathrm{~m}$ inward from each end of the pan. The rest of the nozzles were placed $1.52 \mathrm{~m}$ apart from the adjacent ones. The water flow rate of each nozzle was $2.52 \mathrm{l} / \mathrm{s}$, which provided a $40 \mathrm{~mm} / \mathrm{min}$ discharge density. The amount of oil in the pan was approximately 3800 liters.

The ambient temperature was $305 \mathrm{~K}$. The first flames appeared at the north end and it took about $50 \mathrm{~s}$ before the flames were established all over the 12.2-m long entire surface. Heating continued another $30 \mathrm{~s}$. After that, the gas heater was turned off and water was discharged at the same time. The free-burn condition in the test (and all the future tests) was different from that of the previous 6 tests. It had been rationalized that a fire protection system would be interlocked with a fire detection system. Once fire was detected, the interlocking system would shut off the external heating system and turn on the water discharge system simultaneously. The $30 \mathrm{~s}$ was regarded as a reasonable time to accomplish that.

It took $25 \mathrm{~s}$ to extinguish the fire. The fire flare-up at the initial response to the water discharge was very intense and the flame height reached over $12 \mathrm{~m}$ momentarily. Fig. 3 shows the fire $25 \mathrm{~s}$ after the entire oil surface was covered with flames. The flame height increased noticeably as time went by. Fig. 4 shows the initial flare-up as water was discharged into the pan.

About $5 \mathrm{~s}$ after extinction of the pan fire, a floor fire started. Spilled oil over the pan was re-ignited by the hot tips of the gas nozzles of the heating system installed under the bottom of the pan. The gas nozzles were in the passages of the spilled oil from the pan. The fire spread out onto the floor surface that was covered with oil. The fire was quite intense and burned itself out in $2 \mathrm{~min}$. Although the surface area covered by fire was ex- 


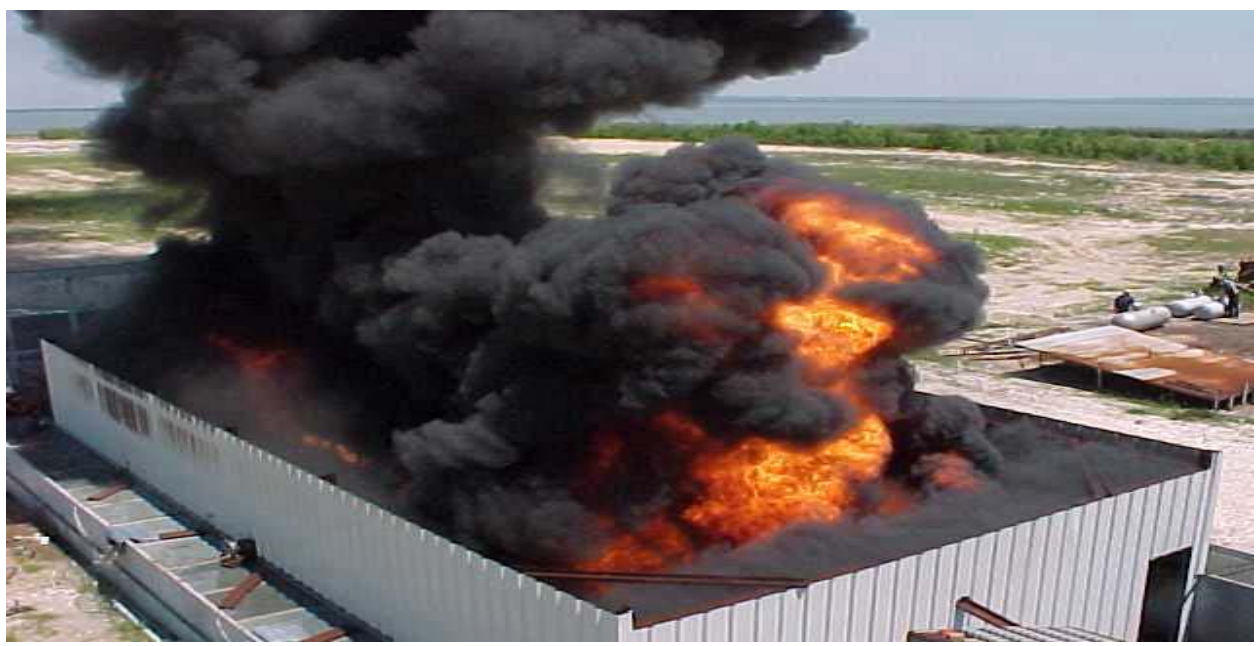

Fig. 3 Free-burn fire progress in Test 7. Fire intensity increased over time. This photo was taken $5 \mathrm{~s}$ before the water discharge.

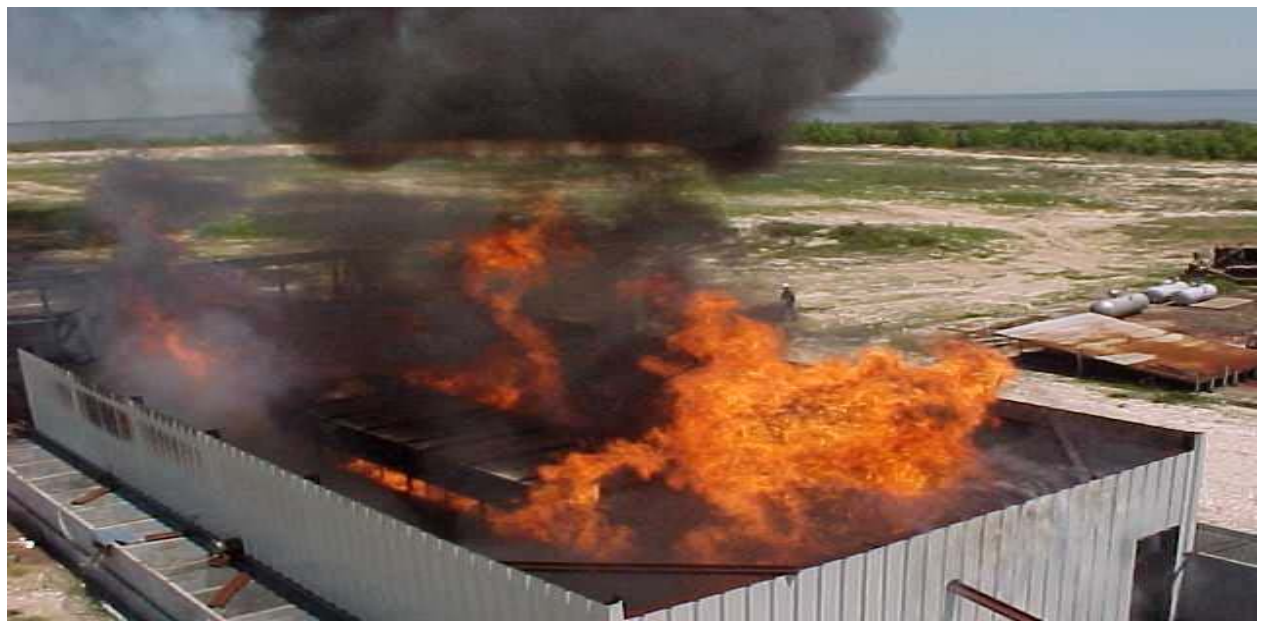

Fig. 4 Fire flare-up due to flame/water reaction in Test 7.

tensive and the fire intensity was severe, the oil inside the pan did not catch fire as the oil already had been cooled down substantially below its flash point.

The temperatures measured $127 \mathrm{~mm}$ above the oil surface showed that the temperatures started to climb $17 \mathrm{~s}$ after water discharge started. This is an indication of the boilingover of the oil at that point. This is believed to be caused by the water that penetrated the oil. The water started to boil up as the boiling point of water was much lower than the temperature of the surrounding oil. The boiling water pushed over the oil in the process. Eventually, the oil was pushed out over the rim of the pan and spilled onto the floor surface after the pan fire was extinguished. The oil cooling time was estimated to be $49 \mathrm{~s}$. 


\subsection{Test 9}

Test 9 used the same test conditions as Test 7 except for the spray nozzles and the discharge density. Instead of eight $13 \mathrm{~mm}$ orifice spray nozzles, sixteen $6.4 \mathrm{~mm}$ orifice spray nozzles $\left(\mathrm{K}=25.9 \mathrm{LPM} /\left[\mathrm{bar}^{1 / 2}\right)\right.$ were installed as shown in Fig. 5. Two rows of the nozzles, eight at each row, were placed along the longitudinal direction $0.76 \mathrm{~m}$ above the oil surface. The water flow rate of each nozzle was $0.63 \mathrm{l} / \mathrm{s}$, which provided a $20 \mathrm{~mm} / \mathrm{min}$ discharge density. The amount of oil in the pan was approximately 3800 liters.

The ambient temperature was $297 \mathrm{~K}$. The flames first appeared at the north end. It took about $1 \mathrm{~min} 7 \mathrm{~s}$ before the flames were established over the entire surface. Heating was provided continuously for another $30 \mathrm{~s}$ before water was discharged. The pan fire was extinguished in $19 \mathrm{~s}$. The fire flare-up at the initial response to the water discharge was very intense. Although the interaction between the fire and the water spray was still very severe, its intensity was noticeably milder compared with that in Test 7.

Extensive oil spilling over the rims of the pan was detected 1 min 18 after the fire extinction. Several floor fires were developed after the pan fire was extinguished and burned themselves out within 10 or $20 \mathrm{~s}$. The ignition source was again the numerous hot burner tips located beneath the pan.

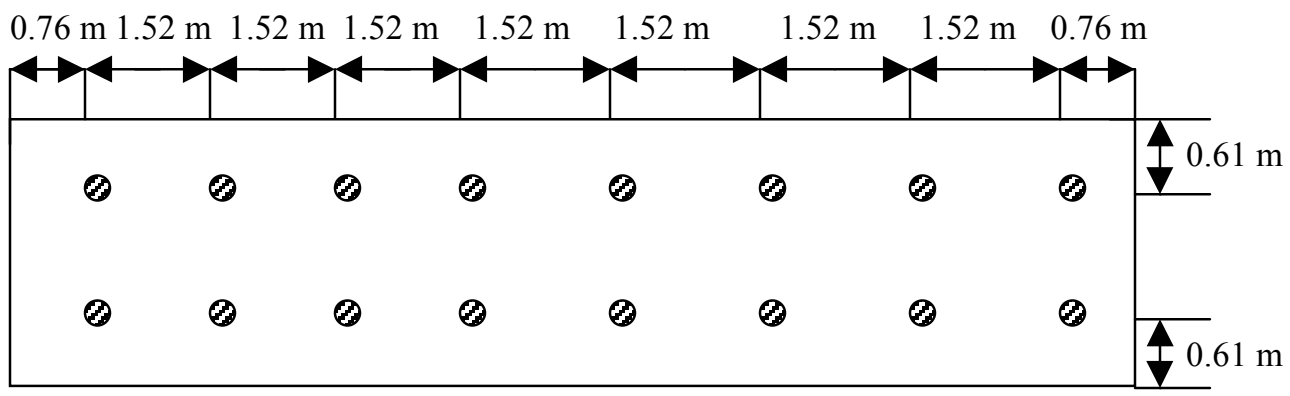

Ø $6.4 \mathrm{~mm}$ orifice spray nozzle (Not to scale)

Fig. 5 Plan view of the pan and nozzle locations in Test 9.

\subsection{Test 10}

Test 10 used Mock-up C with the "hood-down" position. The hood was lowered by $0.41 \mathrm{~m}$ from the "hood-up" position, with which all the previous tests were conducted. The gap between the rim of the pan and the bottom of the hood was reduced to $0.05 \mathrm{~m}$. Accordingly, all sixteen 6.4-mm spray nozzles were also lowered from the previous position. They were relocated $0.38 \mathrm{~m}$ above the surface of the oil. The longitudinal and transverse nozzle locations and the water flow rate were the same as those in Test 9.

The ambient temperature was $299 \mathrm{~K}$. The flames first appeared in the middle of the pan. The whole surface was appeared to be involved in fire within $2 \mathrm{~min}$. After another $30 \mathrm{~s}$ of 
the heating, water was discharged. Fire flare-up at the initial response to the water discharge appeared to be very intense. It took $34 \mathrm{~s}$ to extinguish the pan fire. The cooling time of the oil inside the pan was estimated to be $74 \mathrm{~s}$. The floor below the pan was involved in fire by the spilled oil while water was being discharged. Many small and medium size floor fires were rekindled on and off frequently and continued until $1 \mathrm{~min}$ after the pan fire extinction.

\subsection{Test 11}

Mock-up A, the pan of which was $3.0 \mathrm{~m}$ long by $2.4 \mathrm{~m}$ wide, was installed inside the test facility with the "hood-up" position. Four stainless steel water spray nozzles $(6.4 \mathrm{~mm}$ orifice) were installed $0.76 \mathrm{~m}$ above the oil surface along two longitudinal rows. Each row was located $0.61 \mathrm{~m}$ inward from each transverse end of the pan. Two nozzles at each row along the longitudinal direction were placed $0.75 \mathrm{~m}$ inward from each end of the pan, thereby maintaining $1.5 \mathrm{~m}$ separation between the nozzles (along the longitudinal direction). The water flow rate of each nozzle was $0.63 \mathrm{l} / \mathrm{s}$, which provided a $20 \mathrm{~mm} / \mathrm{min}$ discharge density. The amount of oil in the pan was approximately 950 liters.

The ambient temperature was $305 \mathrm{~K}$. The pan fire was extinguished $10 \mathrm{~s}$ after the water discharge. Extensive oil spilling over the pan was appeared through the video cameras 2 min after the fire extinction. Fig. 6 shows the temperatures measured at Tree 1. Tree 1 was located $1.0 \mathrm{~m}$ from the north end of the pan along the longitudinal axis. $\mathrm{Z}$ in the figure stands for an elevation from the bottom of the pan. Water discharge was initiated at $\mathrm{t}=340 \mathrm{~s}$ in the figure. The temperature measurements at $127 \mathrm{~mm}$ above the oil surface $(Z=254 \mathrm{~mm})$ suggested that it took about $45 \mathrm{~s}$ before the oil started to climb up the free board. The cooling time of the oil inside the pan was estimated to be $118 \mathrm{~s}$.

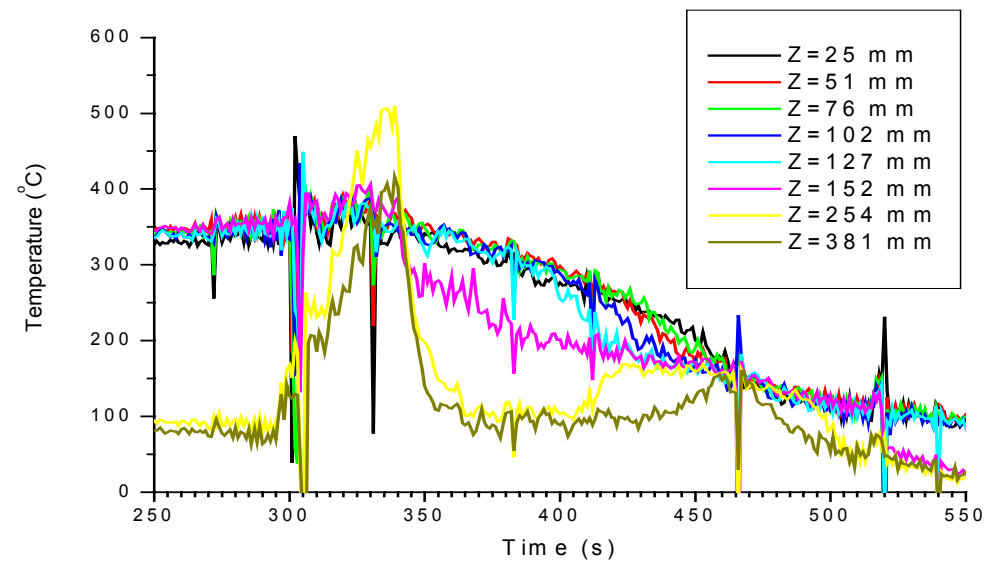

\subsection{Test 13}

Fig. 6 Temperature measurements at Tree 1 in Test 11. 
Test 13 was conducted with test conditions identical to the conditions of Test 11, except for the elevation of the spray nozzles. The nozzles were lowered to $0.38 \mathrm{~m}$ above the oil surface. The ambient temperature was $299 \mathrm{~K}$. The pan fire was extinguished $15 \mathrm{~s}$ after water discharge. Extensive oil spilling over the pan was detected $1 \mathrm{~min}$ after the fire extinction for about $40 \mathrm{~s}$. The spilled oil re-ignited and burned itself out in $40 \mathrm{~s}$. The estimated cooling time of the oil inside the pan was $96 \mathrm{~s}$.

\subsection{Test 14}

Test 14 was conducted with test conditions identical to the conditions of Test 11, except for the spray nozzles. Instead of four $6.4 \mathrm{~mm}$ orifice nozzles, a single $13 \mathrm{~mm}$ orifice spray nozzle was placed at the center of the pan $0.76 \mathrm{~m}$ above the oil surface. The water flow rate at the nozzle was $2.52 \mathrm{l} / \mathrm{s}$, which provided $20 \mathrm{~mm} / \mathrm{min}$ discharge density. The ambient temperature was $300 \mathrm{~K}$. The pan fire was extinguished $29 \mathrm{~s}$ after water discharge. Extensive oil spilling over the pan was first detected $1 \mathrm{~min}$ after the fire extinction. The spilled oil on the floor re-ignited and burned itself out in $1 \mathrm{~min}$.

\section{SUMMARY AND CONCLUSIONS}

Fourteen full-scale fire tests were conducted to find a protection scheme using a waterbased system against self-ignited large industrial oil cooker fires. All but one of the test fires were self-ignited by heating Canola oil inside a pan. After pre-determined free-burn periods, water was discharged through sprinklers or spray nozzles into the burning oil. In most tests, rapid fire extinction was achieved. Fire flare-up at the moment of water discharge was very severe, and the interaction between fire and water spray after the flareup was quite intense. Oil spilling over the pan after pan fire extinction was very pronounced. It is believed that water that penetrated through the hot oil boiled over and pushed the oil over the pan. In all the tests, the oil inside the pan was never re-ignited by the floor fires, which were caused by re-ignition of the spilled oil on the floor. The temperatures of the oil inside the pan were low enough not to catch fire as a result of continuous water discharge.

Test results are summarized in Table 1. The columns in Table 1 show test number, pan length, protection scheme employed (the numbers in the parenthesis are the nozzle orifice size), water discharge density, nozzle elevation above the oil surface, pan fire extinction time, oil cooling time, and the position of the hood in each test.

Since many tests were conducted with different water discharge densities, the pan fire extinction time and the pan oil cooling time alone cannot describe a system's performance fairly. In order to compare each system's performance in the tests, extinction index and cooling index, both dimensionless terms, are given in Table 2 . The extinction index is the total volume of water that was required to achieve fire extinction over the pan, divided by the total volume of the oil inside the pan. The cooling index is the total volume of water that was required to have the oil temperature inside the pan lower than $473 \mathrm{~K}$, divided by the total volume of the oil inside the pan. Thus, a system with a lower extinction or cooling index reflects a more efficient use of water in achieving extinction or cooling as 
compared to a system with a higher index. These indices should not be regarded, however, as an absolute reflection of system performance, as the test conditions were not exactly consistent in every test.

Table 2 also shows the list of average oil temperatures measured at a specified depth from the oil surface at each extinction time in the tests. The measurements show that most of the temperatures at $102 \mathrm{~mm}$ below the oil surface were lower than the ones at $76 \mathrm{~mm}$ and $51 \mathrm{~mm}$ below the surface. This indicates that the water discharged through the nozzles had already penetrated the oil when extinction occurred. This also provides an explanation as to how the oil spilling over the pan occurred.

TABLE 1: FIRE TEST RESULTS

\begin{tabular}{|c|c|l|c|c|c|c|c|}
\hline $\begin{array}{l}\text { Test } \\
\#\end{array}$ & $\begin{array}{l}\text { Pan } \\
(\mathrm{m})\end{array}$ & $\begin{array}{l}\text { Protection } \\
\text { Scheme }\end{array}$ & $\begin{array}{l}\text { Density } \\
(\mathrm{mm} / \mathrm{min})\end{array}$ & $\begin{array}{l}\text { Nozzle } \\
\text { Elev. (m) }\end{array}$ & Ext. (s) & Cool. (s) & Hood \\
\hline 5 & 6.1 & $\begin{array}{l}4 \text { nozzles } \\
(13 \mathrm{~mm})\end{array}$ & 30 & 0.76 & 32 & 52 & Up \\
\hline 6 & 6.1 & $\begin{array}{l}2 \text { nozzles } \\
(13 \mathrm{~mm})\end{array}$ & 8.5 & 0.76 & 145 & 195 & Up \\
\hline 7 & 12.2 & $\begin{array}{l}8 \text { nozzles } \\
(13 \mathrm{~mm})\end{array}$ & 40 & 0.76 & 25 & 49 & Up \\
\hline 9 & 12.2 & $\begin{array}{l}16 \text { nozzles } \\
(6.4 \mathrm{~mm})\end{array}$ & 20 & 0.76 & 19 & 93 & Up \\
\hline 10 & 12.2 & $\begin{array}{l}16 \text { nozzles } \\
(6.4 \mathrm{~mm})\end{array}$ & 20 & 0.38 & 34 & 75 & Down \\
\hline 11 & 3.0 & $\begin{array}{l}4 \text { nozzles } \\
(6.4 \mathrm{~mm})\end{array}$ & 20 & 0.76 & 10 & 118 & Up \\
\hline 13 & 3.0 & $\begin{array}{l}4 \text { nozzles } \\
(6.4 \mathrm{~mm})\end{array}$ & 20 & 0.38 & 15 & 96 & Up \\
\hline 14 & 3.0 & $\begin{array}{l}1 \text { nozzle } \\
(13 \mathrm{~mm})\end{array}$ & 20 & 0.76 & 29 & 88 & Up \\
\hline
\end{tabular}

TABLE 2: AVG. OIL TEMPERATURES AT EXTINCTION; EXTINCTION INDEX AND COOLING INDEX

\begin{tabular}{|c|c|c|c|c|c|c|c|c|}
\hline \multirow{2}{*}{\multicolumn{2}{|c|}{ Depth $(\mathrm{mm})$}} & \multicolumn{5}{|c|}{ Avg. Oil Temp. at Extinction (K) } & \multirow[t]{2}{*}{$\begin{array}{l}\text { Ext. } \\
\text { Index }\end{array}$} & \multirow[t]{2}{*}{$\begin{array}{l}\text { Cool. } \\
\text { Index }\end{array}$} \\
\hline & & 0 & 25 & 51 & 76 & 102 & & \\
\hline & 5 & & & & 540 & 546 & 0.12 & 0.20 \\
\hline & 6 & & & & 484 & 484 & 0.16 & 0.22 \\
\hline $\mathrm{T}$ & 7 & 489 & 537 & $\overline{582}$ & 590 & 578 & 0.13 & 0.26 \\
\hline \multirow{3}{*}{$\begin{array}{l}\mathrm{E} \\
\mathrm{S} \\
\mathrm{T}\end{array}$} & 9 & 585 & 599 & 607 & 605 & 587 & 0.05 & 0.25 \\
\hline & 10 & 535 & 565 & 584 & 586 & 583 & 0.09 & 0.20 \\
\hline & 11 & 612 & 602 & 622 & 622 & 617 & 0.03 & 0.32 \\
\hline \multirow{2}{*}{ \# } & 13 & 604 & 605 & 626 & 628 & 606 & 0.04 & 0.26 \\
\hline & 14 & 564 & 572 & 583 & 593 & 572 & 0.08 & 0.24 \\
\hline
\end{tabular}


Some conclusions based on the fire tests are as follows:

1. Among the systems tested, the ones using 6.4-mm orifice spray nozzles installed in a double-row $0.76 \mathrm{~m}$ above the oil surface, discharging $0.63 \mathrm{l} / \mathrm{s}$ each and maintaining $20 \mathrm{~mm} / \mathrm{min}$ discharge density, provided the best protection in terms of: (1) extinction time, (2) extinction index, and (3) fire reactivity against water discharge.

2. The nozzles placed as close as $0.38 \mathrm{~m}$ above the oil surface required a considerably longer extinction time as compared to the nozzles placed $0.76 \mathrm{~m}$ above the surface.

3. Coverage of water spray over the oil surface seemed to play a very important role in fire extinction. A system providing a greater coverage with a lower discharge density (1) extinguished fire sooner, and (2) resulted in milder fire flare-up, as compared to a system with a higher discharge density providing a lesser coverage.

4. When tests were conducted with the same type of water spray system, a higher discharge density resulted in a shorter extinction time.

5. When two mock-ups having different sizes were subjected to tests with the same discharge density provided by the identical spray nozzles, the mock-up having a larger size needed a longer extinction time.

6. A system relying on nozzles with a smaller orifice diameter seemed to achieve better extinction than systems relying on nozzles with a larger orifice diameter. However, this comparison appeared to be reversed when achieving cooling of the oil inside a pan after extinction.

7. Bronze sprinklers were damaged by a single exposure to a test fire. The frames of bronze water spray nozzles were melted down after they were exposed to several repeat test fires. Stainless steel sprinklers did not show any sign of damage after they were exposed to a test fire. None of the stainless steel spray nozzles used in the tests showed any sign of damage after they were exposed to many repeat test fires.

8. Long exposure of oil to fire seemed to significantly lower the auto-ignition temperature of the oil. This would make it difficult for an oil fire to be extinguished. The importance of quick extinction and fast cooling of self-ignited oil fire was manifested.

\section{REFERENCES}

1. "Oil Cookers," FM Global Property Loss Prevention Data Sheets 7-20, FM Global Insurance Company, Johnston, Rhode Island, USA, 2001.

2. S. Nam, "Application of Water Sprays to Industrial Oil Cooker Fires," Technical Report J. I. 3005113, Factory Mutual Research Corporation, Norwood, Massachusetts, USA, 2001.

3. Interoffice Correspondence, To P. M. Fitzgerald from D. W. Lewin, Subject: Perdue Farms, Inc., December 20, 1988, Factory Mutual Research Corporation, Norwood, Massachusetts, USA.

4. Construction Innovation, Vol. 4, No. 3. National Research Council, Ottawa, Canada, 1999. 